\title{
Overheating Problem Identified
}

National Cancer Institute

\section{Source}

National Cancer Institute. Overheating Problem Identified. NCI Thesaurus. Code

C139520.

The device was found to become hotter than expected during operation. This applies to devices which are not intended to deliver heat. 